\title{
Identification of enhanced hydrogen and ethanol Escherichia coli producer strains in a glycerol-based medium by screening in single-knock out mutant collections
}

\author{
Antonio Valle ${ }^{1 *}$, Gema Cabrera ${ }^{2}$, Domingo Cantero ${ }^{2}$ and Jorge Bolivar ${ }^{1 *}$
}

\begin{abstract}
Background: Earth's climate is warming as a result of anthropogenic emissions of greenhouse gases from fossil fuel combustion. Bioenergy, which includes biodiesel, biohydrogen and bioethanol, has emerged as a sustainable alternative fuel source. For this reason, in recent years biodiesel production has become widespread but this industry currently generates a huge amount of glycerol as a by-product, which has become an environmental problem in its own right. A feasible possibility to solve this problem is the use of waste glycerol as a carbon source for microbial transformation into biofuels such as hydrogen and ethanol. For instance, Escherichia coli is a microorganism that can synthesize these compounds under anaerobic conditions.
\end{abstract}

Results: In this work an experimental procedure was established for screening E. coli single mutants to identify strains with enhanced ethanol and/or $\mathrm{H}_{2}$ productions compared to the wild type strain. In an initial screening of 150 single mutants, 12 novel strains ( $g$ nd, $t d c E$, rpiA nanE, $t d c B$, deoB, sucB, cpsG, frmA, glgC, fumA and gadB) were found to provide enhanced yields for at least one of the target products. The mutations, that improve most significantly the parameters evaluated (gnd and $t d c E$ genes), were combined with other mutations in three engineered $E$. coli mutant strains in order to further redirect carbon flux towards the desired products.

Conclusions: This methodology can be a useful tool to disclose the metabolic pathways that are more susceptible to manipulation in order to obtain higher molar yields of hydrogen and ethanol using glycerol as main carbon source in multiple E. coli mutants.

Keywords: Escherichia coli, Ethanol, Glycerol, High throughput, Hydrogen

\section{Background}

Earth's climate is warming as a result of anthropogenic emissions of greenhouse gases, particularly carbon dioxide $\left(\mathrm{CO}_{2}\right)$ from fossil fuel combustion. Significant opportunities to mitigate anthropogenic emissions of these gases exist, although some will be easier to exploit

\footnotetext{
*Correspondence: antonio.valle@uca.es; jorge.bolivar@uca.es ${ }^{1}$ Department of Biomedicine, Biotechnology and Public Health-Biochemistry and Molecular Biology, Campus de Excelencia Internacional Agroalimentario (ceiA3), Institute of Biomolecules, University of Cádiz, Avda República Saharui s/n, 11510 Puerto Real, Cádiz, Spain

Full list of author information is available at the end of the article
}

than others [1]. Recently, the production and use of biofuels like biodiesel and bioethanol have become widespread because they are more sustainable, secure, renewable, and environmentally safe than the fossil fuels $[2,3]$. Hydrogen $\left(\mathrm{H}_{2}\right)$ is also universally recognized as an environmental friendly and safe renewable resource [4]. Therefore, the production of $\mathrm{H}_{2}$ and ethanol from biomass will probably play an important role in bioenergy generation [5]. However, although biodiesel production has emerged as a possible alternative to fossil fuels, this industry generates glycerol as a by-product in such large quantities that its market value has dropped and it has become an environmental problem in its own right. For 
these reasons, several practical processes for the conversion of glycerol into high-value products have been proposed [6]. In this regard, glycerol represents a cheap carbon source that has been used in several biotransformation processes for the production of added-value products $[2,7-16]$ including the generation of hydrogen and ethanol $[17,18]$.

Escherichia coli-one of the most commonly host organism used for metabolic engineering and biotechnological applications [19-21]-is a suitable species for glycerol utilization either under aerobic or anaerobic conditions [14, 22]. The fermentation of glycerol starts with its conversion to DHAP, which is mediated by a two-branch pathway: the oxidative branch by glycerol dehydrogenase and dihydroxyacetone kinase enzymes; and the reductive branch by glycerol kinase and glycerol 3-phosphate dehydrogenase enzymes. Then DHAP can be then metabolized in the glycolysis pathway to pyruvate. In this process $2 \mathrm{NAD}^{+}$are reduced, one of them in the assimilation of glycerol and another one in the synthesis of 1,3 bisphosphoglycerate.

Ethanol and $\mathrm{H}_{2}$ are originated in E. coli after the anaerobic mixed-acid fermentation in which pyruvate, the final product of glycolysis, is fermented to formate, the substrate for $\mathrm{H}_{2}$ synthesis, and acetyl-CoA, which after two reductive steps is transformed to ethanol in which two NADH are re-oxidized balancing in this way the $\mathrm{NADH} / \mathrm{NAD}^{+}$ratio during the assimilation of glycerol $[14,22]$.

Several factors regulate the production of hydrogen and ethanol. Among them: $\mathrm{pH}$, metabolites transport from or into the cell $[23,24]$, and the carbon source. In this sense, it has been described that hydrogen production by the hydrogenase enzymes (Hyd-1, 2, 3 and 4) in E. coli is influenced by $\mathrm{pH}$ and for instance optimal $\mathrm{pH}$ of activity for the Hyd-3 is around pH 6.5 [2, 25, 26]. On the other hand, glycerol metabolization is enhanced at neutral $\mathrm{pH}$ and is highly active at alkaline $\mathrm{pH}$ [22]. Several relevant studies have also revealed how the hydrogen and ethanol yields can be improved by genetic engineering in $E$. coli $[22,27-30]$. For instance it has been recently described that the deletion of transporters of precursors, such as the formic transporter FocA and FocB, can improve the production of ethanol and/or $\mathrm{H}_{2}[23,24,31]$. Other strategies have consisted on the blockage of one or several pathways involved in the synthesis of competitive products $[21-24,28,32-34]$ and/or the overexpression of enzymes or transcription factors. For instance, the overexpression of genes involved in the uptake and conversion of glycerol (GldA) and/or expression of hydrogenase transcriptional factors (FhlA) can help to redirect the carbon flux towards the production of these target products [22, 24, 28, 32, 33]. Both strategies have been successfully combined and, for instance, Tran et al. [23] have described recently a multiple mutant $E$. coli strain that increases the molar yield for hydrogen and ethanol production.

Metabolic reactions operate as a network rather than linear pathways. When a microorganism is used for the bioproduction of compounds such as $\mathrm{H}_{2}$ and ethanol, the wild type organism often renders suboptimal and unsatisfactory yields. For this reason, metabolic engineering is an emerging field whose objective is to alter the metabolic network through genetic modification in order to improve the production of biofuels such as ethanol, butanol, propanol, biodiesel and hydrogen [35]. When an experimental design in metabolic engineering is aimed towards the production of a specific product, the resulting phenotypes are often suboptimal and unsatisfactory due to the distant effects of genetic modifications or unknown regulatory interactions [36]. In contrast, genetic high-throughput screenings can reveal unexpected genetic backgrounds that are suitable for the production of a particular desired compound. These techniques also have the potential to disclose interactions between different metabolic pathways.

In order to understand the role of the protein-encoding genes in the metabolism, it is useful to study the loss of function by analysing gene knockout phenotypes. Due to the lack of available information in databases concerning growth and multi-omics data for $E$. coli grown under anaerobic conditions in a glycerol based-medium, in the work described here a robust and reproducible experimental design has been established for screening of $E$. coli single mutant strains that allowed the characterization of $\mathrm{H}_{2}$ and ethanol productions together with the glycerol consumption. In this design, the use of minireactors under anaerobic standardized conditions coupled to automated gas chromatography (GC) and high performance liquid chromatography (HPLC) allowed the easy and reliable measurement of hydrogen, ethanol and glycerol.

In this work an initial screening of 150 single knockout strains from the Keio and Yale Collections, was carried out and 12 novel mutants with enhanced ethanol and/or $\mathrm{H}_{2}$ production and/or glycerol consumption respect to the $E$. coli wild type strain were found. Moreover, based on these results, several multiple mutant strains have also been engineered in order to improve the target product yields and the consumption of glycerol.

This design could be applied in a more extensive screening, which might provide useful genetic backgrounds for the production of $\mathrm{H}_{2}$ and ethanol and will help to understand further the physiology of glycerol uptake under anaerobic conditions. 


\section{Results}

\section{Selection of mutants for analysis from the KEIO and YALE} collections

In this study, 150 isogenic E. coli single knockout mutant strains were cultured under the experimental conditions described in Additional file 1: Figure S1. Each mutant strain was tested in triplicate in every set of experiments and a triplicate of the wild type strain was also analysed as a quality control (QC). The preselection of the mutants for analysis was based mainly on genes related to the central carbon metabolism pathways such as glycolysis (8 strains), TCA cycle (20 strains), pentose phosphate pathway (PPP) (13 strains) and intermediate metabolism pathways such as amino acid (20 strains), nucleotide (13 strains) and lipid (13 strains) pathways, although genes involved in other cellular functions were also studied. In this pre-selection some single mutant strains related to the synthesis of hydrogen and ethanol and the assimilation of glycerol were also included (13 strains) and used as experimental controls, since mutants of the same genes have previously been reported to produce higher or lower values for the target products. All of the selected knockout genes are listed in Additional file 2: Table S1.

\section{Ethanol and $\mathrm{H}_{2}$ productions and glycerol consumption in the experimental control strains}

An overview of the experimental control strain values for the target products (Figure 1) showed that the experimental design proposed in this work was appropriate. Thus, the strains defective in enzymes involved in ethanol and $\mathrm{H}_{2}$ synthesis and glycerol consumption-that have previously been reported to produce lower yields-namely formate hydrogenolyase (Fhl) [37], pyruvate formate lyase (PflB) [2], glyceraldehyde 3P dehydrogenase (GldABC), dihydroxyacetone kinase (DhaKL) [13], and formate dehydrogenase (FdhF) and formate hydrogenolyase transcriptional factor (FhlA) [13], consistently showed the lowest values for the specific production of the target products as well as the specific consumption of glycerol. On the other hand, the focA, ldhA, frdC [23] frdA [14] and frdB [38] mutants, which were previously described as efficient $\mathrm{H}_{2}$ and/or ethanol producers, showed higher values for these parameters than the wild type reference which is also shown in Figure 1.

\section{Novel genetic backgrounds suitable for $\mathrm{H}_{2}$ and ethanol production and glycerol consumption}

In order to determine which of the screened mutants showed statistically significant higher values for $Y_{E / X}$ and/or $\mathrm{Y}_{\mathrm{G} / \mathrm{X}}$ and/or $\mathrm{Y}_{\mathrm{H} 2 / \mathrm{X}}$ than those of the wild type strain, the non-parametric contrast Mann-Whitney U test was applied to these parameters. From this analysis it was concluded that 45 mutants (including the experimental control strains) showed statistically significant higher values for any of the target products (Additional file 3: Table S3) and all of them showed values for growth rate $(\mu)>0$ (Additional file 4: Figure S2).

Nevertheless, the number of experiments carried out for each strain was too low $(n=3)$ to use more robust parametrical analysis such as Student's $t$ test. For this reason, the strains included in the 50th percentile (24 mutants) for each target product (Additional file 3: Table S3) were tested further $(n \geq 6)$ and the data obtained were analysed in box plots (Figure 2).

In order to study the interrelation of the three parameters analysed in this work, the $\mathrm{Y}_{\mathrm{H} 2 / \mathrm{X}}, \mathrm{Y}_{\mathrm{E} / \mathrm{X}}$ and $\mathrm{Y}_{\mathrm{G} / \mathrm{X}}$ values for each of these strains and the experimental controls ( $f r d A, f r d B, f r d C$ and $l d h A$ mutants) were related to the wild type ones and subsequently plotted in the cumulative bar chart shown in Figure 3. These experimental control strains consistently showed similar increased values for at least one of the parameters studied in this work (Additional File 5: Table S4) as previously described in the literature [13, 23, 39, 40]. On the other hand, the remaining 12 mutants (gnd, $t d c E, \operatorname{rpi} A$ nanE, $t d c B$, deoB, sucB, cpsG, frmA, glgC, fum $A$ and $\operatorname{gad} B$ ) had not previously been related with the parameters studied in this work. The strains with enhanced values for the three parameters respect to the wild type strain were the $g n d, t d c E, \operatorname{rpi} A, n a n E$ and deoB mutants.

The $t d c B$ mutant increased the glycerol and ethanol yields. In other cases only one of the analysed parameters was improved: the $s u c B$ and cpsG mutants for ethanol, the fum $A$ mutant for hydrogen and the $\operatorname{gad} B, \operatorname{frm} A$ and $g l g C$ mutants for glycerol consumption (Figure 3 ).

Regarding the values of the cumulative bars, the selected mutants could be separated into three different groups: (1) the gnd, frdC and frdB mutants increased values by more than $100 \%$ with respect to the wild type (between 1.12- and 1.43-folds for any of the parameters respect to the wild type); (2) the $t d c E$ mutant increased values by more than $50 \%$ (from 1.1 - up to 1.18 -folds respect to the wild type in any of the parameters) and (3) the $r p i A, n a n E, t d c B$, deoB, frdA, ldhA, sucB, cpsG, frm $A, \operatorname{glg} C$, fum $A$ and gadB mutants showed an increase of $<50 \%$ than that of the wild type (Figure 3 ). Consequently, the gnd mutant (1.43- and 1.31-folds in ethanol and hydrogen production respectively at $46 \mathrm{~h}$ ) and $t d c E$ mutant (1.19-folds at $46 \mathrm{~h}$ and 1.12-folds at $22 \mathrm{~h}$ in ethanol and hydrogen production respectively) were selected as novel potential genetic backgrounds for further studies. 


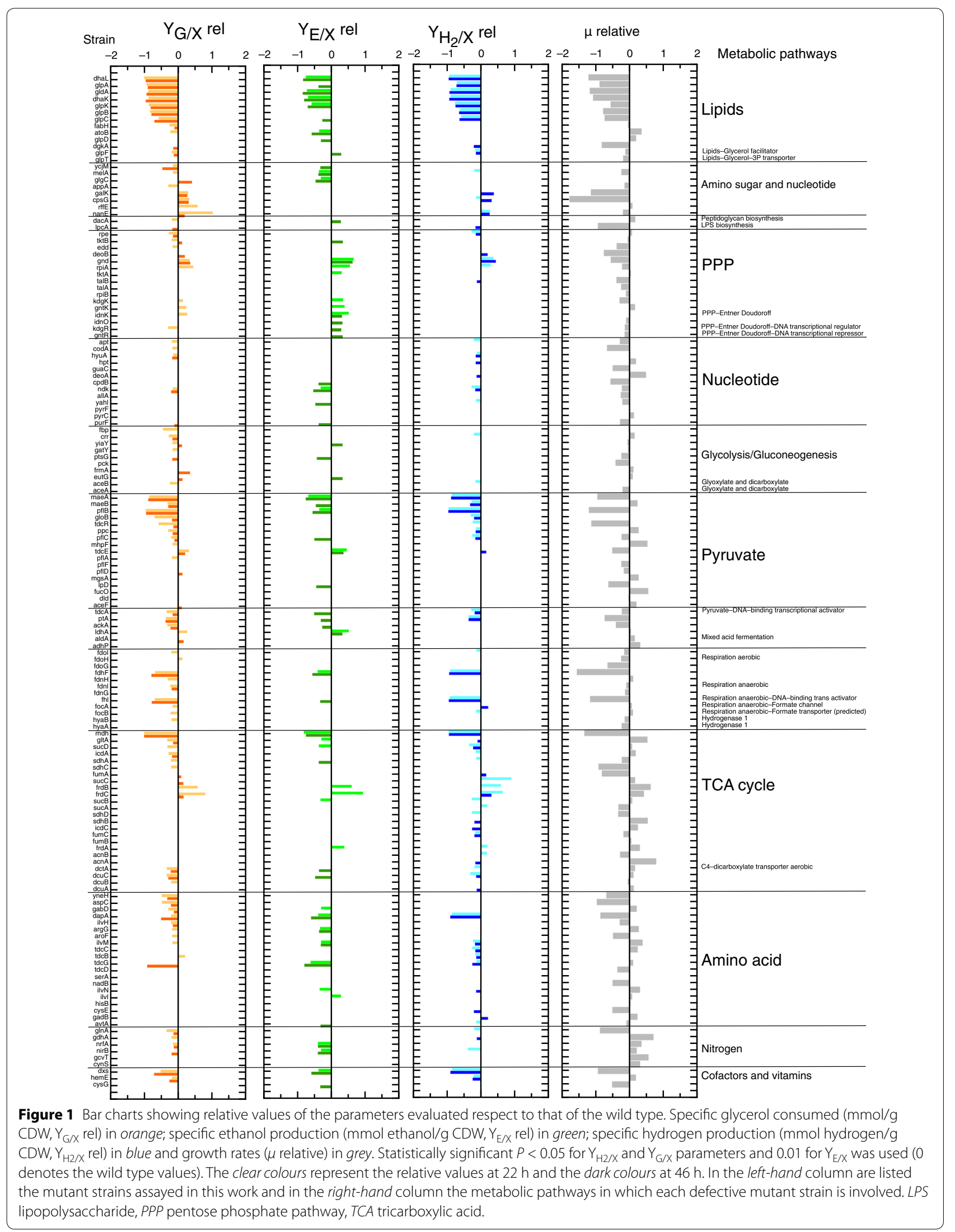




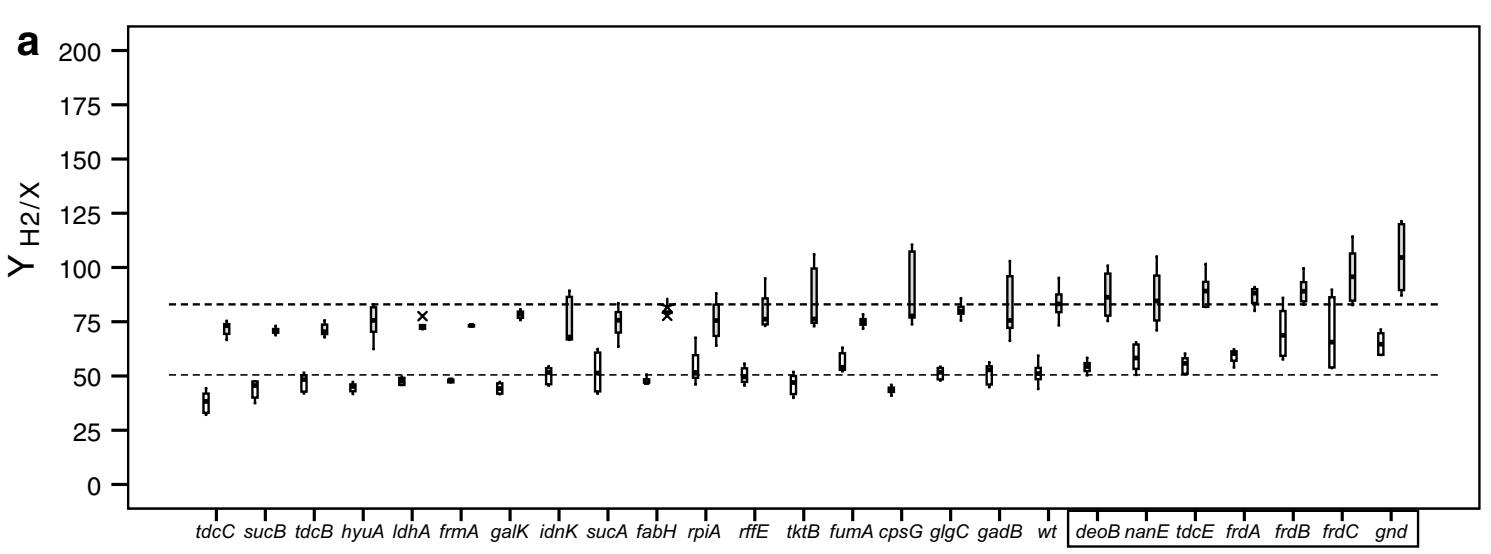

\section{Strains}
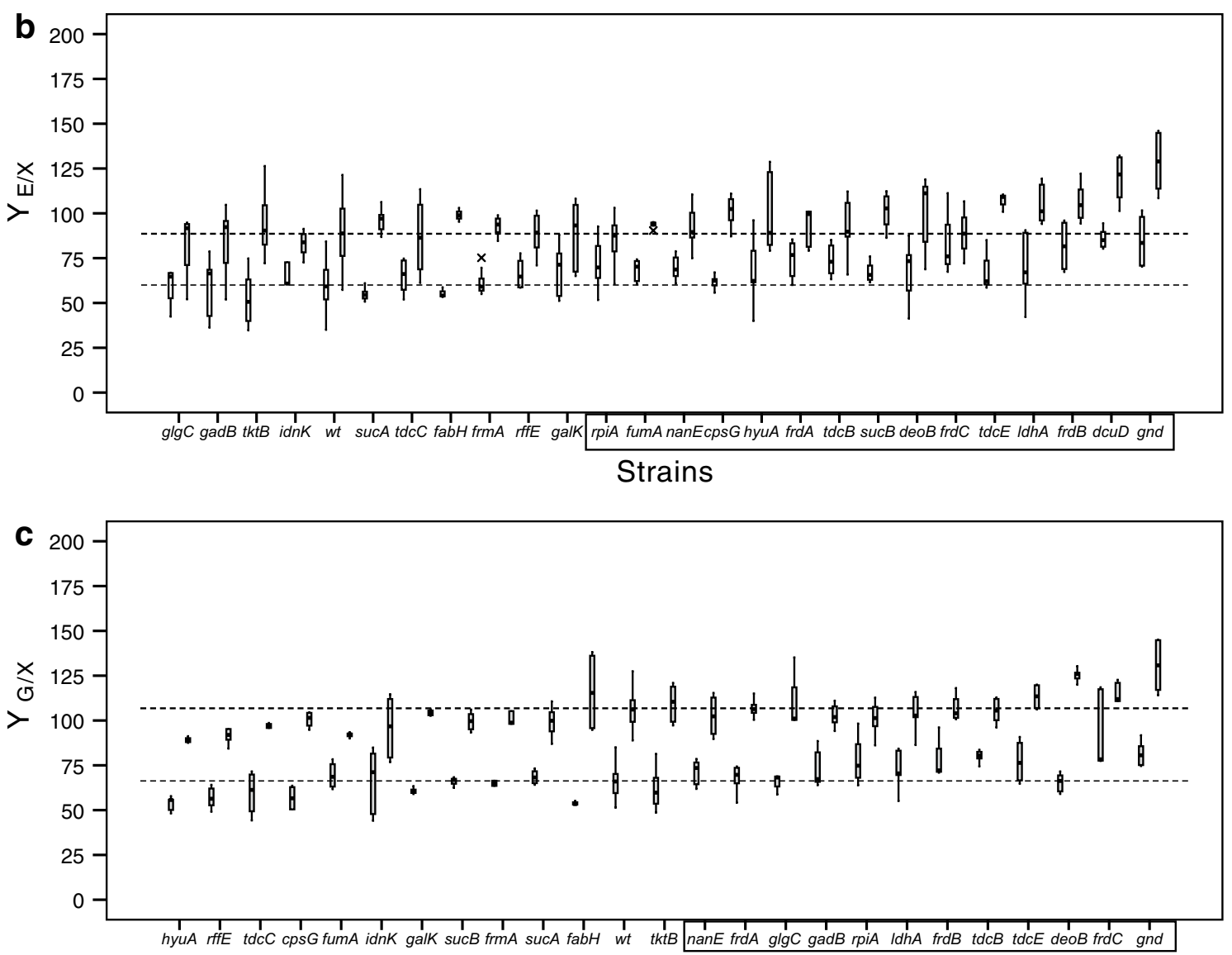

\section{Strains}

Figure 2 Box plots of parameters evaluated in the selected mutant and wild type strains. Specific hydrogen production (mmol hydrogen/g CDW, $\left.\mathrm{Y}_{\mathrm{H} 2 / \mathrm{X}}\right)(\mathbf{a})$, specific ethanol production (mmol ethanol/g CDW, $\left.Y_{E / X}\right)(\mathbf{b})$ and specific glycerol consumption (mmol glycerol consumed/g CDW, $\mathrm{Y}_{\mathrm{G} / \mathrm{X}}$ ) (c). In each graph the white and black boxes represent the 22 and $46 \mathrm{~h}$ interquartile range values respectively and bars the SD. The dashed lines in each graph indicate the wild type averages for each parameter at 22 and $46 \mathrm{~h}$. In the X-axis, the strains whose average values are higher with statistical significance in comparison to that of the wild type using a $P<0.05$ were framed. The wild type data was obtained from at least 75 replicates and the coefficient of variation (CV) was $<11 \%$ for all parameters, except for ethanol concentration, which was lower than $21 \%$. These results were considered to be suitable to establish a reference for comparison of the mutant strain average values with respect to those obtained for the wild type. 


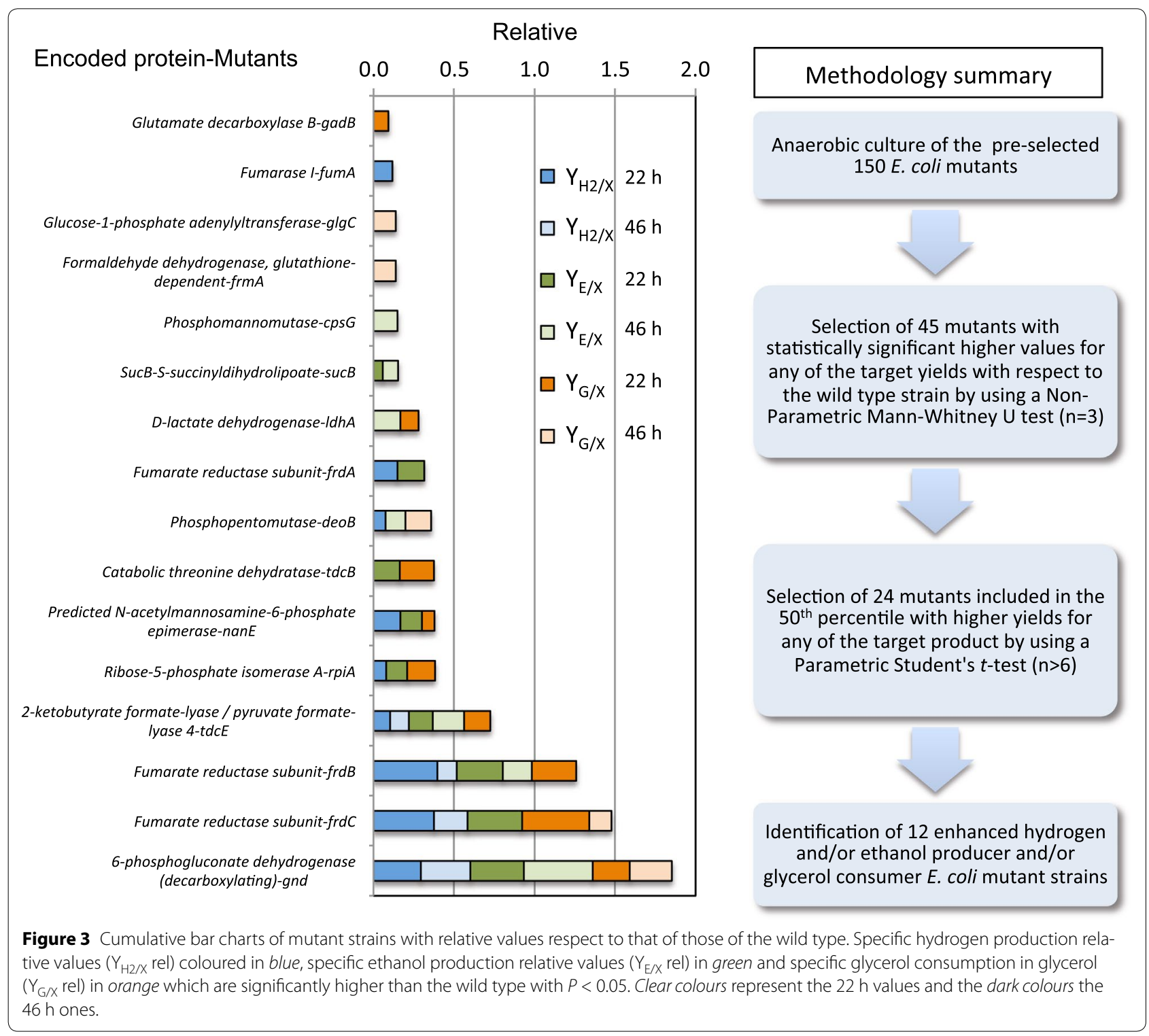

\section{Construction of multiple mutant strains by knocking out the IdhA, gnd, frdBC and $t d c E$ genes}

One of the strategies commonly used in E. coli to improve target product yields is to combine multiple mutations that may help to the redirection of carbon flux towards the synthesis of the desired products. To this aim, the following multiple mutants were constructed; ldhAgnd::kan, ldhAgndfrdBC::kan and ldhAgndfrdBCtdcE::kan denoted in this work as M2, M4 and M5 respectively. On the other hand, another variable that can be considered is the $\mathrm{pH}$ condition. In this sense, the same culture medium but at $\mathrm{pH} 7.5$ was analysed as one of the possible variables that could increase the glycerol consumption [14, $22]$ in the multiple mutant strains. With this purpose, the specific productions for ethanol and hydrogen and glycerol consumption were previously evaluated in the wild type strain up to $94 \mathrm{~h}$ (Additional file 6: Figure S3). In these analysis, although specific hydrogen production $\left(\mathrm{Y}_{\mathrm{H} 2 / \mathrm{X}}\right)$ expressed in mmol of $\mathrm{H}_{2} / \mathrm{g} C D W$ values did not show significant differences between at both $\mathrm{pH}$ (Additional file 6: Figure S3A), the specific ethanol production $\left(\mathrm{Y}_{\mathrm{E} / \mathrm{X}}\right)$ in $\mathrm{mmol}$ of ethanol/g CDW and glycerol consumption $\left(\mathrm{Y}_{\mathrm{G} / \mathrm{X}}\right)$ in mmol of glycerol consumed/g CDW, were significantly higher at $\mathrm{pH} 7.5$ than those obtained at $\mathrm{pH}$ 6.25 from $22 \mathrm{~h}$ on (Additional file 6: Figure S3B and C). Therefore the assays with the multiple M2, M4 and M5, the single gnd and $t d c E$ mutants and wild type strains, were conducted at $\mathrm{pH} 7.5$. 
Although the $\mathrm{Y}_{\mathrm{H} 2 / \mathrm{X}}$ and $\mathrm{Y}_{\mathrm{E} / \mathrm{X}}$ in M4 and M5 at $94 \mathrm{~h}$ were significantly lower $(0.9$-folds for both parameters respect to the wild type) than that of the $g n d, t d c E$ single mutants and for the wild type strain (Figure 4a, c). The molar yields of hydrogen-expressed in mmol of product per mmol of glycerol consumed-was higher for M2 1.07 -fold at $22 \mathrm{~h}$ and for M5 1.22-fold at $70 \mathrm{~h}$ and 1.33fold at $94 \mathrm{~h}$ respect to that of the wild type strain and were also higher than those obtained with M4, gnd, and $t d c E$ mutants (Figure 4b). Regarding to ethanol molar yields it was found that a value for the wild type strain showed a maximum value of 1.1, which is higher than the theoretical value of 1 . This effect can be explained by the fact that the culture medium used in this work is not a minimal medium and, together with glycerol, includes peptone, which can be used by the cells as $\mathrm{C}$ source for ethanol production. In the case of M5, ethanol molar yield values were enhanced 1.41-fold from
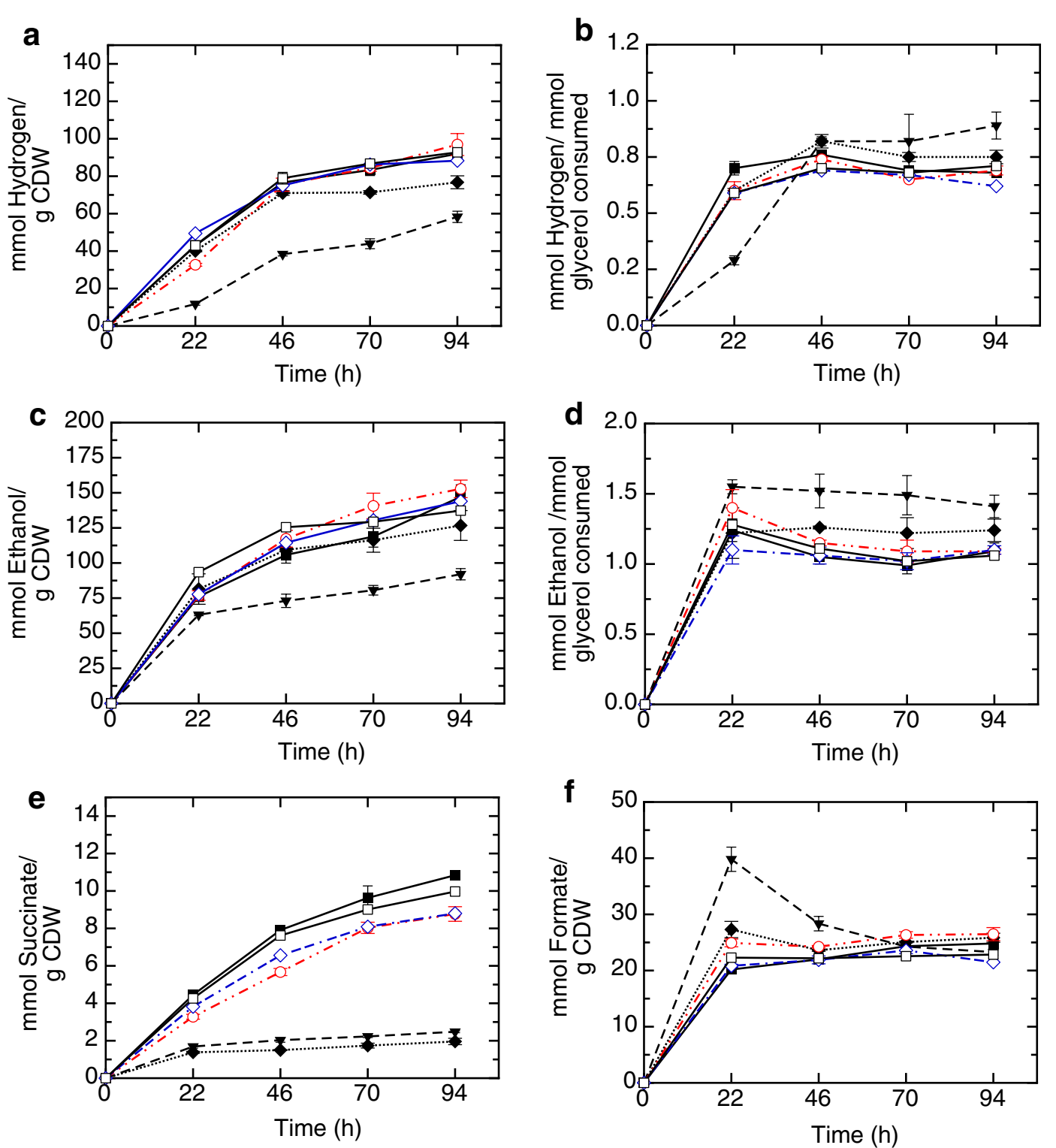

Figure 4 Scatter plots of mean and SD of parameters evaluated in single mutant, multiple mutant and wild type strains. Specific hydrogen production, $Y_{\mathrm{H} 2 / \mathrm{X}}(\mathbf{a})$; hydrogen molar yield $(\mathbf{b})$; specific ethanol production, $\mathrm{Y}_{\mathrm{E} / \mathrm{X}}(\mathbf{c})$; ethanol molar yield (d); specific succinate effluX, $\mathrm{Y}_{\mathrm{S} / \mathrm{X}}(\mathbf{e})$; and specific formate effluX, $Y_{F / X}(\mathbf{f})$; graphed up to $94 \mathrm{~h}$ in the following mutant and wild type strains: IdhAgnd::kan (M2) (filled square); IdhAgndfrdBC::kan (M4) (filled diamonds); IdhAgndfrdBCtdcE::kan (M5) (filled inverted triangle); gnd mutant (open circle); tdcE mutant (open square) and wild type strain (open diamond). Time points evaluated were 22, 46, 70 and $94 \mathrm{~h}$ of experiment. 
$22 \mathrm{~h}$ up to $94 \mathrm{~h}$ respect to the wild type and they were also higher than those obtained respect to the other analysed mutant strains (Figure 4d). On the other hand, M5 showed a higher standard deviation (SD) at 70 and $94 \mathrm{~h}$ for hydrogen yields and at 46, 70 and $94 \mathrm{~h}$ for ethanol yields compared to those obtained at $22 \mathrm{~h}$ (Figure $4 \mathrm{~b}$, d). This relatively high SD is probably due to a biological variability of this mutant strain in the glycerol consumption since specific production for hydrogen and ethanol (Figure 4a, c) showed very low standard deviation.

In order to better understand the redirection of the carbon rewiring, formate-a precursor of hydrogen synthesis - and succinate-the final product of TCA reductive branch-were analysed in the culture medium. These products are actively exported out from the cell in anaerobic conditions. As can be expected, succinate efflux $\left(\mathrm{Y}_{\mathrm{S} / \mathrm{X}}\right)(\mathrm{mmol} / \mathrm{g} \mathrm{CDW})$ was significantly lower for M4 and M5 0.22- and 0.28-fold respectively compare to that of the wild type at $94 \mathrm{~h}$, which are defective in the fumarate reductase enzyme. On the other hand, the M2 showed higher values, 1.23 -fold respect to those of the gnd mutant and wild type strain at $94 \mathrm{~h}$ (Figure $4 \mathrm{e}$ ). In the case of extracellular formate $\left(\mathrm{Y}_{\mathrm{F} / \mathrm{X}}\right)$ expressed in $\mathrm{mmol} / \mathrm{g}$ CDW, the M5 strain showed significantly higher values, up to twofold, at $22 \mathrm{~h}$ than those obtained for the M2, and wild type strains and 1.5-fold respect to $M 4, t d c E$ and gnd mutants. These values gradually decreased and eventually reached similar values to that of the gnd mutant at $94 \mathrm{~h}$ (Figure 4f).

\section{Discussion}

The recent development of two knockout E. coli collections-the Keio Collection and Yale University CGSC Stock Center [41, 42]-has allowed the systematic search of phenotypes in diverse conditions. Recent advances in high-throughput omic technologies have led to the possibility of deciphering an organism's genotype-tophenotype relationships [43]. However, obtaining useful biological knowledge from a single type of omic datafor example, DNA microarray only-is not an easy task. In this work we propose a design for a high-throughput methodology for the systematic analysis of $E$. coli knockout strains for the study of hydrogen and ethanol synthesis and glycerol consumption in order to identify novel $E$. coli phenotypes with enhanced yields for these parameters (Figure 5). In order to test this design, a preliminary screening of 150 single mutants $(n=3)$ from collection strains (Additional file 2: Table S1) was carried out in this work. This methodological design was considered suitable for our purpose due to its reproducibility. In order to validate the experimental procedure, several mutants used as experimental controls (Figure 1), consistently showed statistically significant differences with respect to the reference strain for the same parameters, which validated this methodology. In addition to the control strains, 45 mutants showed statistically significant enhanced parameters (non-parametric test) for one or more of the target products (Figure 1). Those mutants in the 50th percentile of these 45 strains, for any of the parameters evaluated, were selected for further analysis (Additional file 3: Table S3). These 19 selected mutants, together with the experimental control strains (ldhA, frd $A, f r d B$ and $f r d C$ mutants), were further tested $(\mathrm{n} \geq 6$ ) by the parametrical $t$ test. In this new analysis the experimental control strains consistently showed increased $\mathrm{Y}_{\mathrm{H} / \mathrm{X}}, \mathrm{Y}_{\mathrm{E} / \mathrm{X}}$ and $\mathrm{Y}_{\mathrm{G} / \mathrm{X}}$ (Figure 2) and also confirmed that 12 out of the 19 mutant strains showed an enhanced ethanol and/or hydrogen production and/or glycerol consumption (gnd, $t d c E$, rpiA nanE, $t d c B$, deoB, sucB, cpsG, frmA, $\operatorname{glg} C, f u m A$ and $\operatorname{gad} B$ ). These mutated genes are mainly related to the metabolism of amino acids, PPP, TCA, gluconeogenesis, amino sugar and nucleotides.

It is remarkable that 2 out of the 12 selected mutant strains were defective in enzymes involved in the PPP, including the gnd mutant-defective for the 6-phosphogluconate dehydrogenase enzyme-for which $\mathrm{Y}_{\mathrm{H} / \mathrm{X}}, \mathrm{Y}_{\mathrm{E} / \mathrm{X}}$ and $\mathrm{Y}_{\mathrm{G} / \mathrm{X}}$ parameters were significantly enhanced at the two times post inoculum studied in this work. A possible explanation for this phenotype may be that the lack of activity of this enzyme can increase the pool of 6-PG, which would lead to an increase in glyceraldehyde 3-P (G3P) and phosphoenolpyruvate (PEP) by the EntnerDoudoroff pathway, which feeds the 'bottom half' of glycolysis [44]. On the other hand, the rpiA mutant (defective in ribulose-5P-isomerase) also increased the three parameters analysed in this work, albeit to a lesser extent than the gnd mutant. The enzyme codified by this gene is involved in the interconversion of ribose-5P to ribulose-5P. The lack of this enzyme could also have a similar effect to that of the gnd mutant, i.e., the increase of glyceraldehyde 3-phosphate (GA3P) and fructose-6P from pentose sources. Another mutant that is related to the metabolism of pentoses was also found in the 12 selected mutants, namely deoB phosphopentomutase mutant, which showed a similar phenotype to that of the rpiA mutant. This enzyme is involved in the catabolism of nucleotides and deoxynucleotides and promotes the interconversion of ribose-1P or deoxyribose-1P to their corresponding $5 \mathrm{P}$ form. It can therefore be concluded from these results that the reorganization of the metabolism through the blocking of several enzymes involving the PPP is a promising possibility for the rewiring of the metabolism in the use of glycerol as the main $C$ source towards pyruvate and, subsequently synthesising acetylCoA and formate which are transformed respectively into ethanol and hydrogen. 


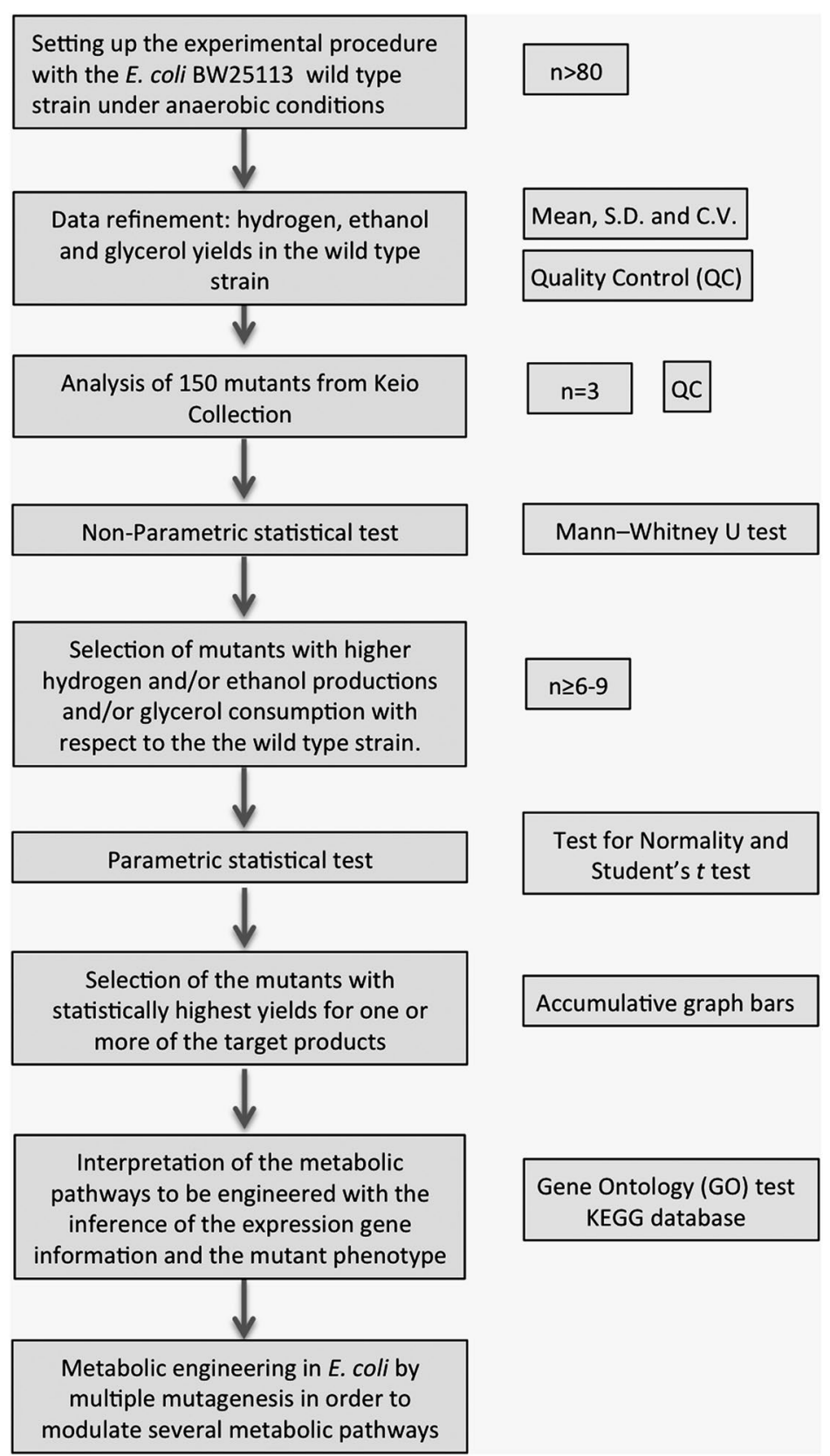

Figure 5 Methodology for a high throughput screening of E. coli mutant strains.

In this screening 39 mutants that involve the nitrogen metabolites were also tested. From these mutants only the $t d c E$ (2-ketobutyrate formate-lyase/pyruvate formate lyase) and the $t d c B$ (threonine dehydratase) mutants, both of which codify enzymes involved in threonine degradation [45], showed enhanced hydrogen yield and glycerol consumption and the $t d c E$ mutant also showed a higher ethanol yield. In this regard, the mutation of any of these enzymes may increase the acetyl-CoA pool and, consequently, the ethanol production. Although not all of the enzymes related to amino acid metabolism were tested, it is significant that two of the selected mutants were related to threonine catabolism. Nevertheless, more in-depth studies are needed to investigate the possibility of rewiring the amino acid metabolism and the rest of the mutants (nanE, deoB, sucB, cpsG, frmA, glgC, fumA, $\operatorname{gad} B$ ) found in this work. 
In order to gain a deeper understanding of which biological functions could be depleted to avoid redundant or deleterious mutations, with the ultimate aim of constructing a multiple mutant strain, these genes were analysed in the Gene Ontology (GO) database [46]. Although several of the GO matches proved to be redundant, the most significant biological processes that were affected were the fermentation, energy derivation by oxidation of organic compounds, generation or precursor metabolites and energy, cell projection, generation of precursor metabolites and energy, oxidation-reduction process and flagella motility among others (Table 1). The results of this analysis seem to indicate that the cells try to rewire the metabolic process to maintain the energy balance, which is translated to the alteration in the synthesis of precursors for the anabolic metabolic processes that cause a decrease in the cell division rate, as can be observed by the relative $\mu$ values for the mutants studied in this work (Additional file 4: Figure S2). In addition, the oxidation-reduction process involving the $\mathrm{NAD}(\mathrm{P}) \mathrm{H} /$ $\operatorname{NAD}(\mathrm{P})^{+}$balance within the cell is fundamental in the equilibrium of glycolysis and fermentation pathways in order to synthesis ATP by level-substrate phosphorylation and also in thousands of energetic-dependent reactions.
Once established the main metabolic pathways, in which these mutants were involved, the gnd and $t d c E$ mutants were selected for further analysis because they showed the higher values in all of the parameters evaluated respect to the wild type strain. One of the strategies commonly used to enhance the efficiency of the biotransformation processes carried out by $E$. coli is the redirection of $\mathrm{C}$-flux by multiple mutations. In this work the mutation of gnd gene (defective in the synthesis of D-Ribulose 5-P) was combined with the deletion of lactate synthesis (ldhAgnd::kan, M2), the succinate synthesis (ldhAgndfrdBC::kan, M4) and the threonine degradation (ldhAgndfrdBCtdcE::kan, M5). These mutant strains together with the reference strain were also evaluated at $\mathrm{pH} 7.5$ due to it has been previously described that glycerol metabolization is favored at this $\mathrm{pH}$ [22]. In the case of M4 and M5 mutants, the blockage of succinate synthesis was observed because in both strains the succinate efflux was substantially decreased (Figure $4 \mathrm{e}$ ) as can be expected from the mutation of $\operatorname{frdBC}$ genes [7, 47]. The hydrogen and ethanol molar yields obtained from these engineered strains, indicates that metabolism of $\mathrm{C}$ source is shunt towards formate, in the case of $g n d$ and $t d c E$ single mutants, M4 and specially M5 mutant in which formate is increased twofold respect wild type strain and 1.5 -fold respect to gnd mutant (Figure 4f).

Table 1 Gene-Ontology (GO) database search in EcoCyc of the knockout mutants selected in based on the statistically significant results of the parameters evaluated shown in Figure 3

\begin{tabular}{|c|c|c|}
\hline Gene-Ontology-terms & p-values ${ }^{a}$ & Matches (mutant strains) \\
\hline Fermentation & $2.22 \mathrm{E}-08$ & IdhA//"frdB"//"frmA"//"frdA"//"frdC" \\
\hline Generation of precursor metabolites and energy & $1.58 \mathrm{E}-07$ & frdB//"tdcE"//"frdA"//"frdC"//"glgC"//"IdhA"//"frmA"//"fumA" \\
\hline Energy derivation by oxidation of organic compounds & $5.45 \mathrm{E}-07$ & $\operatorname{frdB} / / " \mathrm{tdcE}$ "//"frdA"//"frdC"//"glgC"//"IdhA"//"frmA" \\
\hline Aspartate family amino acid catabolic process & $2.02 \mathrm{E}-05$ & $\operatorname{sucB} / / " t d c B^{\prime \prime} / /^{\prime \prime} t d c E^{\prime \prime}$ \\
\hline Bacterial-type flagellum assembly & $2.57 \mathrm{E}-05$ & $\operatorname{frdA} /{ }^{\prime \prime} \mathrm{frdB} \mathrm{B}^{\prime \prime} /{ }^{\prime \prime} \mathrm{frd} C^{\prime \prime}$ \\
\hline Ethanol metabolic process & 5.57E-05 & IdhA//"frmA" \\
\hline Oxidation-reduction process & $6.95 \mathrm{E}-05$ & gnd//"rpiA"//"frdB"//"tdcE"//"frdA"//"frdC"//"glgC"//"IdhA"//"frmA" \\
\hline Single-organism metabolic process & 9.44E-05 & $\begin{array}{l}\text { rpiA//"gnd"//"deoB"//"gadB"//"tdcB"//"frdB"//"tdcE"//"frdA"//"frdC"//"glgC"//"frmA"//"cps } \\
\text { G"//IdhA"//"sucB"//"nanE" }\end{array}$ \\
\hline Single-organism catabolic process & $1.52 \mathrm{E}-04$ & IdhA//"gnd"//"rpiA"//"deoB"//"tdcB"//"sucB"//"tdcE"//"nanE"//"frmA" \\
\hline Tricarboxylic acid cycle & 1.57E-04 & fumA//"frdB"//"sucB" \\
\hline L-threonine catabolic process to propionate & $3.86 \mathrm{E}-04$ & $t d c B / / " t d c E^{\prime \prime}$ \\
\hline Anaerobic respiration & $4.10 E-04$ & $\operatorname{frdB} / /{ }^{\prime \prime} t d c E^{\prime \prime} / /{ }^{\prime \prime} \mathrm{fr} d A^{\prime \prime} / /{ }^{\prime \prime} \mathrm{fr} d C^{\prime \prime}$ \\
\hline Organic substance catabolic process & $6.34 \mathrm{E}-04$ & frmA//"tdcB"//"sucB"//"tdcE"//"IdhA"//"gnd"//"rpiA"//"nanE"//"deoB" \\
\hline Glucose catabolic process & $6.49 \mathrm{E}-04$ & IdhA//"gnd"//"rpiA" \\
\hline Cell motility & $8.04 \mathrm{E}-04$ & $\operatorname{frdA} / /^{\prime \prime} \mathrm{frdB} B^{\prime \prime} /{ }^{\prime \prime} \mathrm{frdC}$ \\
\hline Carbohydrate metabolic process & $8.48 \mathrm{E}-04$ & rpiA//"gnd"//"IdhA"//"glgC"//"cpsG"//"nanE"//"tdcE" \\
\hline Small molecule metabolic process & $8.52 \mathrm{E}-04$ & frmA//"cpsG"//"deoB"//"gnd"//"rpiA"//"IdhA"//"gadB"//"tdcB"//"sucB"//"tdcE"//"nanE" \\
\hline Cellular metabolic process & $8.65 \mathrm{E}-04$ & $\begin{array}{l}\operatorname{deoB} / / \text { "frdB"//"tdcE"//"frdA"//"frdC"//"frmA"//"gnd"//"rpiA"//"cpsG"//"glgC"//"IdhA"//"gad } \\
\text { B"//"tdcB"//"nanE"//"sucB"//"fumA" }\end{array}$ \\
\hline Cellular respiration & $9.59 \mathrm{E}-04$ & $\operatorname{frdB} / / " t d c E^{\prime \prime} / /{ }^{\prime \prime} r d A^{\prime \prime} / /{ }^{\prime \prime} f r d C^{\prime \prime}$ \\
\hline
\end{tabular}

a The matches were found using a $P<0.001$ which are denoted as scientific notation $(E)$. 
This effect correlated with an enhanced ethanol molar yield in the M5 mutant (1.41-fold respect to that of the wild type) (Figure 4d). This improvement is higher than that obtained in the septuplet mutant (BW25113frdC $l d h A$ fdnG ppc narG $m g s A, h y c A$ ) reported by Tran et al. [23] (0.67-fold respect to the wild type at $24 \mathrm{~h})$. The only difference between M4 and M5 strains is the deletion of TdcE enzyme gene, which is involved in catabolism of threonine into propanoate [45]. This deletion in M5 may provoke a significant metabolic redirectionthrough unknown metabolic regulation mechanismstowards pyruvate and subsequently to formate-which is exported out the cell- and acetyl-CoA that is converted more efficiently into ethanol (Figure 4d). The excess of formate is exported out the cell due to accumulation of this molecule in the cell to toxic levels, although after $22 \mathrm{~h}$ could be imported $[31,48]$ and then converted to hydrogen (Figure 4a). In fact, the M5 strain growth was significantly depleted after $22 \mathrm{~h}$ (Additional file 7: Figure S4) and specific productions were very low respect to all the analysed strains (Figure $4 \mathrm{a}, \mathrm{c}$ ). In this mutant the higher molar yield measured for hydrogen and ethanol could mean that glycerol consumption was lower, although the metabolization of this product is more efficient in M5 mutant than in the wild type. In this sense M5 mutant could be an interesting genetic background for further studies in which the excess of formate may be converted into hydrogen.

\section{Conclusion}

In conclusion, the systematic analysis of the target products in E. coli mutant strains proposed in this work is a feasible methodology to identify novel suitable genetic backgrounds to enhance the synthesis of hydrogen and/ or ethanol in cells cultured in a glycerol-based medium. In this work we identified several mutants (chiefly gnd, and the $t d c E$ ) that could be combined in multiple mutant strains in order to enhance the yields of the desired products by metabolic engineering. This kind of studies can also help to understand the metabolic rewiring to reveal the pathways that are most susceptible to genetic modification, which could in turn facilitate the design of more efficient strategies to engineer $E$. coli strains.

\section{Methods}

\section{Bacterial strains and chemicals}

The strain BW25113 was used as the wild type strain in this work. Isogenic single-gene knock out derivatives [48] were obtained from the National Bioresource Project, Keio Collection (NIG, Japan) and from the Coli Genetic Stock Center (CGSC) (Yale University, USA) [41] and they are listed in Additional file 2: Table S1.
Molecular and functional information for the metabolic pathways used in this work was compiled from the Kyoto Encyclopaedia of Genes and Genomes (KEGG) (http://www.genome.jp/kegg/) [49] and EcoCyc (http:// ecocyc.org/) [50].

Kanamycin (Kan) was purchased from Gibco ${ }^{\mathrm{TM}}$ (Invitrogen, UK) and was used for pre-culturing the isogenic knockouts with chromosomal kan resistance markers $\left(\mathrm{Kan}^{\mathrm{R}}\right)$ at a concentration of $50 \mu \mathrm{g} \mathrm{mL}^{-1}$. The chemicals used for the culture media were as follows: peptone, yeast extracts, agar-agar were obtained from Panreac (PANREAC QUIMICA S.A., Spain) and $\mathrm{KH}_{2} \mathrm{PO}_{4}, \mathrm{Na}_{2} \mathrm{HPO}_{4}$ (extra pure), $\mathrm{Na}_{2} \mathrm{SO}_{4}, \mathrm{NaCl}, \mathrm{MgSO}_{4} 7 \mathrm{H}_{2} \mathrm{O}$ and glycerol (food grade 99\% extra pure) were obtained from Scharlau (Scharlab S.L., Spain).

\section{Culture conditions}

Escherichia coli knock out strains listed in Additional file 2: Table S1 were initially streaked from $-80^{\circ} \mathrm{C}$ glycerol stocks on LB agar plates containing Kan. Knock out mutations were checked by PCR [50]. Cultures for all of the experiments were incubated in an orbital incubator shaker at $200 \mathrm{rpm}$ and $37^{\circ} \mathrm{C}$.

For the screening of 150 single mutant strains, a fresh single colony was inoculated in $2 \mathrm{~mL}$ Luria-Bertani (LB) medium supplemented with Kan and the colony was cultured overnight. This aerobic pre-culture was used to inoculate the bacteria under microaerobic conditions in LB-glycerol medium [11] in $50 \mathrm{~mL}$ Falcom tubes (VWR International Eurolab S.L., Spain). These cells were centrifuged at $4,900 \times g$ for $15 \mathrm{~min}$ at $4^{\circ} \mathrm{C}$ (Sigma $2 \mathrm{~K} 15$, Laborzentrifugen $\mathrm{GmbH}, \mathrm{Germany})$. Inside an anaerobic glove box, previously purged with Ar to diminish the oxygen level to below $1 \%$, the pellet obtained was suspended in approximately $40 \mathrm{~mL}$ glycerol-based medium [11], $\left(\mathrm{KH}_{2} \mathrm{PO}_{4}, 7.19 \mathrm{~g} \mathrm{~L}^{-1} ; \mathrm{Na}_{2} \mathrm{HPO}_{4}, 1.98 \mathrm{~g} \mathrm{~L}^{-1}\right.$; $\mathrm{Na}_{2} \mathrm{SO}_{4}, 0.0806 \mathrm{~g} \mathrm{~L}^{-1}$; NaCl, $0.0152 \mathrm{~g} \mathrm{~L}^{-1} ; \mathrm{MgSO}_{4} 7 \mathrm{H}_{2} \mathrm{O}$, $0.031 \mathrm{~g} \mathrm{~L}^{-1}$; glycerol $10 \mathrm{~g} \mathrm{~L}^{-1}(109 \mathrm{mM})$ and peptone $4.25 \mathrm{~g} \mathrm{~L}^{-1}, \mathrm{pH}$ 6.25) previously sparged with Ar for $5 \mathrm{~min}$, in order to obtain an $\mathrm{OD}_{600 \mathrm{~nm}}$ of $0.83 \pm 0.025$. These cells were poured into $12 \mathrm{~mL}$ crimp-top vials and sealed with a butyl rubber septum and aluminium caps. Both LB-glycerol and glycerol-based medium were previously sparged with argon (Ar) gas (99.9\%) for 5 min to ensure that they were completely deprived of $\mathrm{O}_{2}$. The wild type and the gnd and the multiple mutant strains were also assayed in the experimental conditions described previously except for the glycerol-based medium $\mathrm{pH}$, which was adjusted at $\mathrm{pH} 7.5$ by using the following salt buffer concentrations: $\mathrm{KH}_{2} \mathrm{PO}_{4}, 1.78 \mathrm{~g} \mathrm{~L}^{-1}$ and $\mathrm{Na}_{2} \mathrm{HPO}_{4}, 7.65 \mathrm{~g} \mathrm{~L}^{-1}$. Triplicates of each E. coli strains were incubated for 22 and $46 \mathrm{~h}$. 


\section{Construction of knock out strains}

The multiple mutants were constructed using the $l d h A::$ kan single mutant as the parental strain following the homologous recombination method described by Datsenko and Wanner [51]. Firstly, the Kan resistance marker inserted in the ldhA mutant strain $(\Delta l d h A$ ::kan) was removed after transformation with the $\mathrm{pCP} 20$ plasmid. Clones were selected by replica plating in LB agar plates supplemented with $\mathrm{Cm}$ or Kan. For plasmid curing, several clones were randomly selected; replica plated in LB agar plates with no antibiotic and incubated at $42^{\circ} \mathrm{C}$. For the multiple strain constructions, $g n d, f r d B C$ and $t d c E$ genes, pairs of primers were designed in order to have short $5^{\prime}(\mathrm{H} 1)$ or $3^{\prime}(\mathrm{H} 2)$ homology sequences of the target genes (in capital letters) that were flanking P4 or P1 priming sequences of the pKD13 vector (in lower case letters) (Additional file 8: Table S2). Using these primers and the $\mathrm{pKD} 13$ vector as the template, PCR products were performed containing the $\mathrm{Kan}^{\mathrm{R}}$ gene and flanked by FLP recognition targets (FRTs). PCR was carried out with Velocity $^{\mathrm{m}}$ DNA polymerase (Bioline Reagents Ltd., London, UK). The PCR-generated products were transformed by electroporation in the strains previously transformed with the pKD46 plasmid. The transformants were then selected in LB agar plates supplemented with Kan. Gene disruptions of the generated mutant strains; were confirmed by PCR amplification by using external and internal primers (Additional file 8: Table S2).

All DNA manipulations were performed according to standard methods [52, 53], plasmid isolation was achieved using the NucleoSpin Plasmid Kit (MachereyNagel, Düren, Germany GmbH \& Co.) and PCR Cleanup was performed with the QIAquick PCR Purification Kit (QUIAGEN, Hilden, Germany).

\section{Analytical techniques and methods}

The volume of gas generated $\left(\mathrm{H}_{2}\right.$ and $\left.\mathrm{CO}_{2}\right)$ in the headspace was measured by inserting a needle, which was connected to a water column manometer, into the rubber septum. Hydrogen quantification in the headspace was measured by injecting $100 \mu \mathrm{L}$ aliquots into a Bruker 450-Gas Chromatograph (GC) equipped with a Poraplot Q Plot FS $25 \times 53$ column and a thermal conductivity detector (TCD) (Bruker Daltonik GmbH, Fahrenheitstr, Germany). The injector and detector were maintained at 250 and $150^{\circ} \mathrm{C}$, respectively and the Ar carrier gas flow rate was maintained at $10 \mathrm{~mL} \mathrm{~min}^{-1}$.

Cell growth was estimated by measuring $\mathrm{OD}_{600 \mathrm{~nm}}$ $(1 \mathrm{OD}=0.31 \mathrm{~g}$ of cell dry weight $(\mathrm{CDW}) / \mathrm{L})$ according to standard procedures [54] on a Spectroquant Pharo 100 spectrophotometer (๔ Merck KGaA, Darmstadt, Germany).
Glycerol, ethanol, succinate and formate efflux, were measured from the supernatant of the samples, filtered through $0.22 \mu \mathrm{m}$ nylon filters, and quantified by HPLC as previously described [11].

\section{Calculation of parameters and statistical analysis}

The raw data for $\mathrm{H}_{2}(\%)$, concentration of ethanol and glycerol consumed $\left(\mathrm{g} \mathrm{L}^{-1}\right)$ and the volume of gas generated $(\mathrm{mL})$ were analysed and were used to calculate the following parameters for the wild type and mutant strains: specific hydrogen $\left(\mathrm{Y}_{\mathrm{H} 2 / \mathrm{X}}\right)$ and ethanol productions $\left(\mathrm{Y}_{\mathrm{E} / \mathrm{X}}\right)$, specific glycerol consumption $\left(\mathrm{Y}_{\mathrm{G} / \mathrm{X}}\right)$ values referred to the biomass $(\mathrm{X})$ ( $\mathrm{g}$ of $\mathrm{CDW}$ ). For the multiple mutant, gnd and $t d c E$ single mutants and wild type strains, succinate $\left(\mathrm{Y}_{\mathrm{S} / \mathrm{X}}\right)$ and formate efflux $\left(\mathrm{Y}_{\mathrm{F} / \mathrm{X}}\right)$ were also calculated and referred to the biomass.

For each parameter the average (m), standard deviation (SD) and the coefficient of variation (CV) were calculated using at least three biological replicates for the mutant strains and at least 75 replicates for the wild type strain. For the experiments with the pre-selected mutant, the statistical analysis for each mutant parameter was considered to be significantly different based on the nonparametric contrast of the Mann-Whitney $U$ test. The $P<0.01$ for $\mathrm{Y}_{\mathrm{E} / \mathrm{X}}$ and $<0.05$ for $\mathrm{Y}_{\mathrm{H} 2 / \mathrm{X}}, \mathrm{CDW}$, and $\mathrm{Y}_{\mathrm{G} / \mathrm{X}}$ parameters were used. The statistically significant values of the $\mathrm{Y}_{\mathrm{H} 2 / \mathrm{X}}, \mathrm{Y}_{\mathrm{E} / \mathrm{X}}, \mathrm{Y}_{\mathrm{G} / \mathrm{X}}$, and $\mu$ parameters ( $\mathrm{Y}$ rel.) were used to relativize the mutant values with the wild type ones $\left(\mathrm{Y}_{\mathrm{mut}}-\mathrm{Y}_{\mathrm{wt}} / \mathrm{Y}_{\mathrm{wt}}\right)$ (wild type denoted as 0 ). The molar yields for $\mathrm{H}_{2}$ and ethanol (mmol product/mmol glycerol consumed) were also calculated in the multiple mutant, gnd and $t d c E$ single mutants, and wild type strains.

For mutant selection on the basis of the best parameter $\left(\mathrm{Y}_{\mathrm{H} 2 / \mathrm{X}}, \mathrm{Y}_{\mathrm{G} / \mathrm{X}}\right.$ and $\mathrm{Y}_{\mathrm{E} / \mathrm{X}}$ results) obtained at 22 and/or $46 \mathrm{~h}$, the distribution of continuous variables was evaluated by the Shapiro-Wilk's normality test and Levene's test for homogeneity of variances was employed to inform the choice of the appropriate statistical test. As conditions for the application of parametric tests, Student's $t$ test was used to evaluate the statistical significance of differences the parameters between the groups. IBM ${ }^{\circ}$ SPSS $^{\circ}$ Statistics 20 software was used for statistical analysis.

Gene Ontology (GO) database information on gene expression was used to provide additional information about the selected mutant phenotypes (Table 1). GO is a database of standardized biological terms used to annotate gene products and it comprises several thousand terms divided into three branches: molecular function, biological process and cellular component. This analysis of putative biological processes was applied to the selected mutants and the assignment of a biological process was restricted to a $P<0.001$ in the Fisher's test was used in this database. 


\section{Additional files}

Additional file 1: Figure S1. In the screening carried out in this work, the culture conditions were first normalized and the procedures for the measurement of the ethanol and hydrogen production and the glycerol consumption were established by a gradual adaptation of the bacteria to anaerobic growth and the use of glycerol as the carbon source. This adaptation process is summarized in four steps; the overnight aerobic pre-culture grown in LB medium (A), $1 \%$ of microaerobic inoculum (E) cultured in LB-glycerol containing a negligible oxygen concentration culture up to $4 \mathrm{~h}$ (B); the anaerobic inoculum, in which the LB-glycerol medium is removed and replaced by the glycerol-based medium (C); and the anaerobic mini-reactors (D); with 60\% headspace was chosen for higher hydrogen production and two time points at 22 and $46 \mathrm{~h}$ postinoculum due to were representative of the LP and SP for the analysis of the target products (F)

Additional file 2: Table S1. List of E. coli knock out mutant strains purchased from Keio and Yale collections.

Additional file 3: Table S3. E. coli mutant strains with significantly higher values of specific hydrogen production $\left(Y_{\mathrm{H} 2 / X}\right)$ in blue, specific ethanol production $\left(Y_{E / X}\right)$ in green and specific glycerol consumption $\left(Y_{G / X}\right)$ in orange with respect to the wild type values. Intensity of colours indicates higher relative values. The 50th percentile of the values are: $14 \%$ and $13 \%$ for the $Y_{H 2 / X}$ at 22 and $46 \mathrm{~h}$, respectively, $47 \%$ and $33 \%$ for the $Y_{E / X}$ at 22 and $46 \mathrm{~h}$ respectively, and $32 \%$ and $20 \%$ for the $Y_{G / X}$ at 22 and $46 \mathrm{~h}$ respectively. The mutant strains selected according to the 50th percentile are marked in bold

Additional file 4: Figure S2. Growth rates $(\mu)$ calculated for the mutants and wild type strain (in frame) ordered from top to bottom in ascendant order.

Additional file 5: Table S4. Relative hydrogen and ethanol production in E. coli mutant strains using different carbon sources and $\mathrm{pH}$.

Additional file 6: Figure S3. Scatter plots of mean and SD of specific hydrogen production, $Y_{\mathrm{H} 2 / \mathrm{X}}(\mathbf{A})$; specific ethanol production, $\mathrm{Y}_{\mathrm{E} / \mathrm{X}}(\mathbf{B})$; and specific glycerol consumption, $Y_{G / X}$ (C) of wild type strain with culture medium at pH 6.25 (filled inverted triangle) and pH 7.5 (open circle).

Additional file 7: Figure S4. Cell dry weight (CDW) curves in $\mathrm{g} / \mathrm{L}$ of the multiple mutants: IdhAgnd::kan (M2) (filled square); IdhAgndfrdBC::kan (M4) (filled diamond); IdhAgndfrdBCtdcE::kan (M5) (filled inverted triangle); the single mutants: gnd (open circle) and tdcE (open square) and the wild type strain (open diamond).

Additional file 8: Table S2. The primers from 1 to 6 were used to obtain multiple mutants; IdhAgnd:kan (M2), IdhAgndfrdBC::kan (M4) and IdhAgndfrdBCtdcE::kan (M5). Capital letters indicate the homologous sequences of the target genes and in lower case letters indicate the priming sequences of the pKD13 vector. In the names of the primers, $\mathrm{H} 2 \mathrm{P} 1$ indicates the forward primers and $\mathrm{H} 1 \mathrm{P} 4$ the reverse primers. Primers from 7 to 15 were used for PCR verification of the deletion of the targeted genes.

\section{Abbreviations}

GLDA: glycerol dehydrogenase; PflB: pyruvate formate lyase; GldABC: glyceraldehyde $3 \mathrm{P}$ dehydrogenase; DhaKL: dihydroxyacetone kinase; FdhF: formate dehydrogenase-H; FhIA: formate hydrogenolyase transcriptional factor; PPP: pentose phosphate pathway; TCA: tricarboxilyc acid cycle; GA3P: glyceraldehyde 3-phosphate; PEP: phosphoenolpyruvate; GO: gene ontology; QC: quality control; $\mu$ : growth rate.

\section{Authors' contributions}

$\mathrm{AV}$ carried out the experimental procedure and the data analysis. AV, JB, DC and GC conceived of the study and participated in its design. JB and AV drafted the manuscript and GC and DC reviewed it. All authors read and approved the final manuscript.

\section{Author details}

${ }^{1}$ Department of Biomedicine, Biotechnology and Public Health-Biochemistry and Molecular Biology, Campus de Excelencia Internacional Agroalimentario (ceiA3), Institute of Biomolecules, University of Cádiz, Avda República Saharui s/n, 11510 Puerto Real, Cádiz, Spain. ${ }^{2}$ Department of Chemical Engineering and Food Technology, Campus de Excelencia Internacional Agroalimentario (ceiA3), University of Cádiz, Avda República Saharui s/n, 11510 Puerto Real, Cádiz, Spain.

\section{Acknowledgements}

This work was supported by the Consejería de Innovación, Ciencia y Empresa de la Junta de Andalucía through the Project for Excellence P09-TEP-4830 (2009) co-funded by FEDER Programme 2007-2013 and the PAIDI groups CTS569 and TEP-105.

\section{Compliance with ethical guidelines}

\section{Competing interest}

The authors declare that they have no competing interests.

Received: 14 May 2015 Accepted: 16 June 2015

Published online: 28 June 2015

\section{References}

1. Montzka SA, Dlugokencky EJ, Butler JH (2011) Non- $\mathrm{CO}_{2}$ greenhouse gases and climate change. Nature 476(7358):43-50

2. Dharmadi Y, Murarka A, Gonzalez R (2006) Anaerobic fermentation of glycerol by Escherichia coli: a new platform for metabolic engineering. Biotechnol Bioeng 94(5):821-829

3. Hansen AC, Zhang Q, Lyne PWL (2005) Ethanol-diesel fuel blends-a review. Bioresour Technol 96(3):277-285

4. Das D, Veziroglu TN (2008) Advances in biological hydrogen production processes. Int J Hydrog Energ 33(21):6046-6057

5. Cai G, Jin B, Monis P, Saint C (2011) Metabolic flux network and analysis of fermentative hydrogen production. Biotechnol Adv 29(4):375-387

6. Johnson DT, Taconi KA (2007) The glycerin glut: options for the valueadded conversion of crude glycerol resulting from biodiesel production. Environ Prog 26(4):338-348

7. Hu H, Wood TK (2010) An evolved Escherichia coli strain for producing hydrogen and ethanol from glycerol. Biochem Biophys Res Commun 391(1):1033-1038

8. Ito T, Nakashimada Y, Senba K, Matsui T, Nishio N (2005) Hydrogen and ethanol production from glycerol-containing wastes discharged after biodiesel manufacturing process. J Biosci Bioeng 100(3):260-265

9. Dasilva G, Mack M, Contiero J (2009) Glycerol: a promising and abundant carbon source for industrial microbiology. Biotechnol Adv 27(1):30-39

10. Yuwa-amornpitakT (2012) Bio-hydrogen production from biodiesel glycerol waste from used oil by bacterium isolated from waste water sludge. J Environ Sci Technol 5(5):373-380

11. Cofré O, Ramírez M, Gómez JM, Cantero D (2012) Optimization of culture media for ethanol production from glycerol by Escherichia coli. Biomass Bioenergy 37:275-281

12. Durnin G, Clomburg J, Yeates Z, Alvarez PJJ, Zygourakis K, Campbell P et al (2009) Understanding and harnessing the microaerobic metabolism of glycerol in Escherichia coli. Biotechnol Bioeng 103(1):148-161

13. Yazdani SS, Gonzalez R (2008) Engineering Escherichia coli for the efficient conversion of glycerol to ethanol and co-products. Metab Eng 10(6):340-351

14. Murarka A, Dharmadi Y, Yazdani SS, Gonzalez R (2008) Fermentative utilization of glycerol by Escherichia coli and its implications for the production of fuels and chemicals. Appl Environ Microbiol 74(4):1124-1135

15. Trchounian K, Trchounian A (2013) Escherichia coli hydrogenase 4 (hyf) and hydrogenase 2 (hyb) contribution in $\mathrm{H}_{2}$ production during mixed carbon (glucose and glycerol) fermentation at $\mathrm{pH} 7.5$ and $\mathrm{pH}$ 5.5. Int J Hydrog Energy 38(10):3921-3929

16. Lee S, Kim S, Kang S, Han S, Park C, Kim S (2012) Effect of crude glycerolderived inhibitors on ethanol production by Enterobacter aerogenes. Bioprocess Biosyst Eng 35(1):85-92 
17. Kim JH, Choi KH, Choi YS (2010) Hydrogen generation from solid $\mathrm{NaBH}_{4}$ with catalytic solution for planar air-breathing proton exchange membrane fuel cells. Int J Hydrog Energy 35(9):4015-4019

18. Panagiotopoulos IA, Bakker RR, Budde MAW, de Vrije T, Claassen PAM, Koukios EG (2009) Fermentative hydrogen production from pretreated biomass: a comparative study. Bioresour Technol 100(24):6331-6338

19. Maeda T, Sanchez-Torres V, Wood TK (2008) Metabolic engineering to enhance bacterial hydrogen production. Microb Biotechnol 1(1):30-39

20. Valle A, Le Borgne S, Bolivar J, Cabrera G, Cantero D (2012) Study of the role played by NfsA, NfsB nitroreductase and NemA flavin reductase from Escherichia coli in the conversion of ethyl 2-(2'-nitrophenoxy)acetate to 4-hydroxy-(2H)-1,4-benzoxazin-3(4H)-one (D-DIBOA), a benzohydroxamic acid with interesting biological properties. Appl Microbiol Biotechnol 94(1):163-171

21. Chen X, Zhou L, Tian K, Kumar A, Singh S, Prior BA et al (2013) Metabolic engineering of Escherichia coli: a sustainable industrial platform for biobased chemical production. Biotechnol Adv 31(8):1200-1223

22. Gonzalez R, Murarka A, Dharmadi Y, Yazdani SS (2008) A new model for the anaerobic fermentation of glycerol in enteric bacteria: trunk and auxiliary pathways in Escherichia coli. Metab Eng 10(5):234-245

23. Tran KT, Maeda T, Wood TK (2014) Metabolic engineering of Escherichia coli to enhance hydrogen production from glycerol. Appl Microbiol Biotechnol 98(10):4757-4770

24. Maeda T, Sanchez-Torres V, Wood TK (2012) Hydrogen production by recombinant Escherichia coli strains. Microb Biotechnol 5(2):214-225

25. Trchounian K (2012) Transcriptional control of hydrogen production during mixed carbon fermentation by hydrogenases 4 (hyf) and 3 (hyc) in Escherichia coli. Gene 506(1):156-160

26. Trchounian K, Sanchez-Torres V, Wood TK, Trchounian A (2011) Escherichia coli hydrogenase activity and $\mathrm{H}_{2}$ production under glycerol fermentation at a low pH. Int J Hydrog Energy 36(7):4323-4331

27. Trchounian K, Poladyan A, Trchounian A (2009) Relation of potassium uptake to proton transport and activity of hydrogenases in Escherichia coli grown at low pH. Biol Membr 26(2):111-118

28. Cintolesi A, Clomburg JM, Rigou V, Zygourakis K, Gonzalez R (2012) Quantitative analysis of the fermentative metabolism of glycerol in Escherichia coli. Biotechnol Bioeng 109(1):187-198

29. Khanna S, Goyal A, Moholkar VS (2012) Microbial conversion of glycerol: present status and future prospects. Crit Rev Biotechnol 32(3):235-262

30. Trchounian K, Soboh B, Sawers RG, Trchounian A (2013) Contribution of hydrogenase 2 to stationary phase $\mathrm{H}_{2}$ production by Escherichia coli during fermentation of glycerol. Cell Biochem Biophys 66(1):103-108

31. Trchounian $K$, Trchounian A (2014) Different role of focA and focB encoding formate channels for hydrogen production by Escherichia coli during glucose or glycerol fermentation. Int J Hydrog Energy 39(36):20987-20991

32. Gonzalez R, Campbell P, Wong M (2010) Production of ethanol from thin stillage by metabolically engineered Escherichia coli. Biotechnol Lett 32(3):405-411

33. Sanchez-Torres V, Mohd Yusoff MZ, Nakano C, Maeda T, Ogawa HI, Wood TK (2013) Influence of Escherichia coli hydrogenases on hydrogen fermentation from glycerol. Int J Hydrog Energy 38(10):3905-3912

34. Trchounian K, Trchounian A (2013) Escherichia coli multiple [Ni-Fe]-hydrogenases are sensitive to osmotic stress during glycerol fermentation but at different pHs. FEBS Lett 587(21):3562-3566

35. Shimizu K (2011) 2.30-metabolic regulation analysis and metabolic engineering. In: Moo-Young M (ed) Comprehensive biotechnology, 2nd edn. Academic Press, Burlington, pp 407-420

36. Garrett RH, Grisham CM (2013) Metabolism: an overview. In: Biochemistry, 5th edn. Brooks/Cole, Cengage Learning, pp 551-573
37. Maeda T, Sanchez-Torres V, Wood TK (2007) Escherichia coli hydrogenase 3 is a reversible enzyme possessing hydrogen uptake and synthesis activities. Appl Microbiol Biotechnol 76(5):1035-1042

38. Agapakis CM, Ducat DC, Boyle PM, Wintermute EH, Way JC, Silver PA (2010) Insulation of a synthetic hydrogen metabolism circuit in bacteria. J Biol Eng. 4(1):3

39. Nikel PI, Ramirez MC, Pettinari MJ, Mendez BS, Galvagno MA (2010) Ethanol synthesis from glycerol by Escherichia coli redox mutants expressing adhE from Leuconostoc mesenteroides. J Appl Microbiol 109(2):492-504

40. Yoshida A, Nishimura T, Kawaguchi H, Inui M, Yukawa H (2006) Enhanced hydrogen production from glucose using $/ d h$ - and frd-inactivated Escherichia coli strains. Appl Microbiol Biotechnol 73(1):67-72

41. Baba T, Ara T, Hasegawa M, Takai Y, Okumura Y, Baba M et al (2006) Construction of Escherichia coli K-12 in-frame, single-gene knockout mutants: the Keio collection. Mol Syst Biol 2:1-11

42. Yamamoto N, Nakahigashi K, Nakamichi T, Yoshino M, Takai Y, Touda Y et al (2009) Update on the Keio collection of Escherichia coli single-gene deletion mutants. Mol Syst Biol 5:335. doi:10.1038/msb.2009.92

43. Yup LS (2009) Systems biology and biotechnology of Escherichia coli. Springer, The Netherlands, pp 6-7

44. Peekhaus N, Conway T (1998) What's for dinner? Entner-Doudoroff metabolism in Escherichia coli. J Bacteriol 180(14):3495-3502

45. Hesslinger C, Fairhurst SA, Sawers G (1998) Novel keto acid formatelyase and propionate kinase enzymes are components of an anaerobic pathway in Escherichia coli that degrades L-threonine to propionate. Mol Microbiol 27(2):477-492

46. Ashburner M, Ball CA, Blake JA, Botstein D, Butler HJ, Cherry M et al (2000) Gene ontology: tool for the unification of biology. The Gene Ontology Consortium. Nat Genet 25(1):25-59

47. Maeda T, Sanchez-Torres V, Wood TK (2007) Enhanced hydrogen production from glucose by metabolically engineered Escherichia coli. Appl Microbiol Biotechnol 77(4):879-890

48. Trchounian A, Gary Sawers R (2014) Novel insights into the bioenergetics of mixed-acid fermentation: can hydrogen and proton cycles combine to help maintain a proton motive force? IUBMB Life 66(1):1-7

49. Kanehisa M, Goto S (2000) KEGG: Kyoto encyclopedia of genes and genomes. Nucleic Acids Res 28(1):27-30

50. Keseler IM, Collado-Vides J, Gama-Castro S, Ingraham J, Paley S, Paulsen IT et al (2005) EcoCyc: a comprehensive database resource for Escherichia coli. Nucleic Acids Res 33(Database issue):D334-D337

51. Datsenko KA, Wanner BL (2000) One-step inactivation of chromosomal genes in Escherichia coli K-12 using PCR products. Proc Natl Acad Sci USA. 97(6):6640-6645

52. Sambrook J, Fritsch E, Maniatis T (1989) Molecular cloning: a laboratory manual, 2nd edn. Cold Spring Harbor Laboratory Press, Cold Spring Harbor

53. Miller JH (1972) Experiments in molecular genetics. Cold Spring Harbor Laboratory Cold Spring Harbor, New York

54. Greenberg AE, Clesceri LS, Eaton AD (1992) Standard methods for the examination of water and wastewater, vol 13, 18th edn. APHA, Washington, p 936

\section{Submit your next manuscript to BioMed Central and take full advantage of:}

- Convenient online submission

- Thorough peer review

- No space constraints or color figure charges

- Immediate publication on acceptance

- Inclusion in PubMed, CAS, Scopus and Google Scholar

- Research which is freely available for redistribution

Submit your manuscript at

www.biomedcentral.com/submit
C Biomed Central 